From officium to civil service position the Difficult Transformation of Rent

Bureaucracy into a Constitutional

Bureaucracy

\title{
Do ofício ao cargo público - a difícil transformação da burocracia prebendária em burocracia constitucional
}

José Reinaldo de Lima Lopes

Professor no Departamento de Filosofia e Teoria Geral do Direito, Faculdade de Direito da Universidade de São Paulo (USP - São Paulo/ Brasil) e na Escola de Direito de São Paulo da Fundação Getúlio Vargas (FGV - São Paulo/Brasil). e-mail: jrlopes@usp.br

\section{Resumo}

0 comentário explora as possiveis semelhanças entre o desenvolvimento do Brasil e das repúblicas hispânicas da América do Sul ao longo do século XIX. Ao contrário dos "Vice Reynados" de língua espanhola, o Brasil tivera uma burocracia pouco desenvolvida no período colonial. Entretanto, com a mudança da Corte portuguesa para o Rio de Janeiro em 1808 a burocracia cresceu mais rápido do que antes. Contudo, cresceu na direção das ideias do antigo regime sobre a organização governamental: justiça, governo, fazenda e guerra. Nessas linhas, foi o serviço da justiça que se organizou melhor, enquanto a fazenda e a defesa cresceram apenas nas últimas décadas do século.

\section{Abstract \\ The paper explores possible similarities between the development of Brazil and the Spanish speaking republics in South America during the XIX century. As opposed to the Spanish speaking "Vice Reynados", Brazil had a rather undeveloped bureaucracy in colonial times. However, as the Portuguese head of government moved to Rio de Janeiro in 1808 bureaucracy grew faster than before. Nonetheless, it grew along the lines of the Ancien Régime ideas of governmental organization: justice, government, fazenda (royal treasury) and war. Along these lines it was the judicial service that was best organized, while the treasury and the military only increased in the last decades of the century.}

Palavras-chave

burocracia, Estado, justiça, monarquia constitucional, século XIX

Keywords

bureaucracy, State, justice, constitutional monarchy, nineteenth century 
1

Sobre o papel governativo das audiências ver LIRA, Bernardino Bravo. Historia de las instituciones políticas de Chile e Hispanoamerica. Santiago: Editorial Andrés Bello, 1986 (esp. p.86-89) e Idem. El absolutismo ilustrado en Hispanoamerica, Chile (1760-1860). Santiago: Editorial Universitária, 1996 (esp. p.52-54).

Um exemplo claro dessa mentalidade encontrase nos primeiros parágrafos das Lectures on jurisprudence de Adam Smith. Para ele todos os governos têm quatro fins: manter a justiça (e, por implicação, a paz interna); uma vez que esta esteja garantida, o governo zela pela opulência do reino, por meio da polícia (incluindo a regulamentação do comércio, das manufaturas, da agricultura); em seguida, como o governo tem certo custo, seu sustento é também parte de sua finalidade (fazenda); finalmente, o governo protege o próprio reino (guerra). As conferencias de Smith correspondem a dois cursos dados entre 1762 e 1764 (SMITH, Lectures on jurisprudence.(ed. R. Meek et al.). Indianápolis: Liberty Fund, 1982). A mesma ordem encontra-se essencialmente nas Instituições de direito civil lusitano público e privado de Melo Freire. Depois de fazer uma lista das fontes (leis, costumes, direito subsidiário, etc), Melo Freire inicia ordenadamente sua exposição do direito público tratando seguidamente da justiça (de judiciis, potestas judiciária) e do direito de punir (ius gladii), do tesouro (aerarium et fiscus), das relações do soberano com a Igreja (jure principis circa sacra), das matérias de polícia (leis agrárias, do comércio e da polícia em geral), terminando com as leis acerca da guerra (cf. FREIRE, Paschoal J. de Melo. Institutiones júris civilis Iusitani cum publici tum privati. $5^{a}$ ed. Coimbra: Editora da Universidade de Coimbra, 1859).

3

Cf. LACOMBE, Américo J. e TAPAJÓS, Vicente. Organização administrativa do Ministério da Justiça no Império. Brasília: Ministério da Justiça / Fundação Centro de Formação do Servidor Público, 1986. p.31.
Há realmente paralelos entre o Brasil e a América hispânica? Sim e não, claro. Como o texto do Prof. Garavaglia articula-se em duas partes, permitam-me tecer meus comentários em torno de sugestões levantadas por ambas. A primeira diz respeito ao fim do periodo colonial. Aqui serei breve, pois no restante do texto procederei do século XVIII para o século XIX, de maneira que os paralelos se deixariam notar mais facilmente. Gostaria, no entanto, de destacar uma importante diferença: a inexistência no Brasil de finais do século XVIII de um grande tribunal, à moda das Audiências. As Audiências eram tribunais judiciários e simultaneamente órgãos de governo. ${ }^{1}$ Embora o Brasil contasse com a Relação da Bahia e a Relação do Rio de Janeiro, as atividades exercidas pelos dois órgãos eram sobretudo judiciárias, jurisdicionais. Isso marca um fato relevante, pois a magistratura, que será sem dúvida um elemento social de ligação entre os dois períodos (colonial e independente, monárquico absoluto e monárquico constitucional liberal), não contava no Brasil nem com instituições de ensino nem com uma carreira de âmbito americano. A formação dos bacharéis dava-se exclusivamente em Coimbra e a carreira da magistratura acontecia com um percurso por todo o Império (América, África, Ásia, Europa). Sem grandes tribunais (no sentido que a historiografia hoje atribui ao termo), sem escolas e sem um cursus honorum doméstico, a situação do Brasil no momento de sua independência difere de seus vizinhos americanos.

Passo agora a tratar de um motivo levantado na segunda parte do texto. Teria havido alguma continuidade entre a "burocracia" colonial e aquela formada após a independência? Para abordar o assunto apresentarei uma síntese das mudanças introduzidas no século XIX em certas áreas do Estado brasileiro.

0 governo do final do século XVIII concentrado que fora no monarca, estava funcionalmente dividido em quatro grandes áreas: Justiça, Governo, Fazenda e Guerra. Antes que divisão de poderes, a bem dizer inexistente na monarquia pré-liberal, entendia-se que o soberano governa por quatro funções: distribuir justiça, defender o reino (guerra), policiar de modo geral e dirigir o reino para o bem (governo) e cuidar do patrimônio comum (fazenda). ${ }^{2}$ Cada um desses ramos tinha seu tribunal próprio: o Conselho de Fazenda, 0 Conselho de Guerra, o Conselho de Justiça e os conselhos de governo, como o Conselho de Estado ou o Conselho Ultramarino. Os Conselhos, diziam os juristas da monarquia pura, representavam os povos na falta das Cortes e exerciam, nas respectivas áreas, atribuições tanto de governo e aconselhamento do príncipe quanto de resolução contenciosa de conflitos. A justiça no sentido estrito (aplicação das penas entre os particulares) está na mão de dois conseIhos, o Desembargo do Paço - órgão de supervisão de toda a máquina judicial, e o grande tribunal do reino, a Casa da Suplicação, sendo que os respectivos regedores funcionavam como administradores das respectivas corporações.

Isso permanece assim por um bom tempo, e a nomenclatura dos secretários de D. João VI mostra apenas três pastas: Reino, Marinha e Ultramar e Guerra e Estrangeiros. ${ }^{3}$ Não por acaso as Cortes Gerais e Constituintes de Lisboa decidem reorganizar a estrutura de governo, criando em 18 de agosto de 1821 a Secretaria de Estado da Justiça. Tinha início o processo de extinção do governo por Conselhos, particularmente, no que me interessa, dos Conselhos de Justiça. No Reino Unido do Brasil, durante a REGÊNCIA de D. Pedro, o ministério também foi reformulado. Por aqui separou-se a pasta de estrangeiros da antiga pasta da Guerra, por exemplo.

No período das independências americanas e da constitucionalização do Brasil isso ainda não era tão claro, mesmo porque a própria ideia de um 
4

Para a história e os dados do Tribunal da Relação do Rio de Janeiro ver WEHLING, Arno e WEHLING, Maria José. Direito e justiça no Brasil: o Tribunal da Relação do Rio de Janeiro (1751-1808). Rio de Janeiro: Renovar, 2004.
Estado constitucional, liberal e burocrático estava sendo experimentada. Em alguns lugares já se havia desenhado algum modelo, mas as primeiras décadas do século XIX não são ainda a do triunfo da burocracia de modelo weberiano. Existem, no entanto, as experiências inspiradoras em áreas que, por exigirem formação profissional e habilidades especificas, poderiam ser a sementeira da nova burocracia: a justiça (juízes e desembargadores), clero (o seminário diocesando de Olinda havia sido restaurado), militares (D. João manda fundar uma academia e uma escola de engenharia militar), e fazenda (lembremos das aulas de comércio cuja origem era de iniciativa já do Marques de Pombal). Outros profissionais havia, como os médicos e os engenheiros, para cuja educação tinham sido criadas escolas durante a estada da Corte no Rio de Janeiro (1808-1821), mas uns e outros não prestavam serviços exclusivamente ao Estado. Havia sido criada também, desde o período pombalino, a Aula de comércio, mas ela também não formava principal e primeiramente servidores do Estado. Examinemos pois aquelas atividades de serviço de Estado propriamente.

Vejamos, em primeiro lugar, a burocracia jurdiciária. A exigência do conhecimento de direito, do grau de bacharel em leis é bem estabelecida em Portugal a partir do século XVI. Creio que não é exagerado dizer que a justiça é realmente a primeira burocracia moderna no Brasil, embora escolas de direito só venham a existir depois de 1827. Isso se revela já em 1808 quando D. João transforma o Tribunal da Relação do Rio de Janeiro em Casa da Suplicação, isto é, no Tribunal mais alto do reino, em pé de igualdade com a Casa da Suplicação de Lisboa, com poderes de definir em última instancia não só os casos concretos, mas o sentido geral das leis por meio de assentos. Criado em 10 de maio de 1808, foi composto por 17 membros e sobreviveu ao turbulento período da Independência e da Constituinte, sendo extinto em 1828, para dar lugar ao Supremo Tribunal de Justiça. Este, por sua vez, foi composto justamente de 17 ministros, 15 dos quais procediam da Casa da Suplicação (dois deles vinham do Desembargo do Paço, também extinto em 1828). Faltam ainda estudos sobre a Casa da Suplicação do Brasil e por isso não tenho aqui elementos para falar da total continuidade de uma instituição na outra, mas pode-se suspeitar de que foi grande. 0 primeiro presidente do Supremo Tribunal de Justiça, nomeado em 1828, é ninguém mais, ninguém menos, do que José Albano Fragoso, o último desembargador nomeado (1807) para o antigo Tribunal da Relação do Rio de Janeiro, ${ }_{1}^{4}$ transformado em Casa da Suplicação do Rio de Janeiro em 1808.

Houve também uma carreira de juizes letrados, os juizes de fora, de primeira instância. Embora odiados por serem instrumentos diretos da intervenção da Coroa nos assuntos locais, constituíram uma importante unidade de corpo - vinda quer da própria profissão, quer de sua socialização em tempos de estudantes na Universidade de Coimbra, única aberta para formar a gente da lei no Império lusitano. Desses letrados provieram os juizes de direito do Império, cuja carreira começa de fato a organizar-se em 1827, com o fim da jurisdição contenciosa das Câmaras, e prossegue com diversas reformas, inclusive com a lei da carreira judiciária de 1850 (Decreto 687), e termina na lei de reforma de 1871 . Esses juízes eram vitalícios, e criaram uma verdadeira burocracia: eram pagos principalmente pelos cofres públicos (vencimentos); mesmo sendo nomeados pelo Ministro da Justiça, sua nomeação dependia de habilitação profissional especifica (bacharelado em direito). Uma vez nomeados, cumpriam um caminho de ascensão hierárquica de comarcas menores para maiores, da primeira para a segunda instância, até, nos limites do 
Sobre o assunto escrevi mais largamente em Governo misto e abolição de privilégios: criando um judiciário no Império. In: OLIVEIRA, Cecilia Helena de Salles; BITTENCOURT, Vera Lúcia Nagig; COSTA, Wilma Peres. (Org.). Soberania e conflito: configurações do Estado nacional no Brasil do século XIX. São Paulo: Editora Hucitec/ Fapesp, 2010.

6

Uma história do exército como burocracia e os conflitos de sua profissionalização com os traços mais típicos do Estado brasileiro do século XIX está feita por Wilma Peres Costa. A espada de Dâmocles: o exército, a guerra do Paraguai e a crise do Império. São Paulo: Hucitec / Ed. Unicamp, 1996.

7

Sobre a Guarda Nacional as referências obrigatórias são, naturalmente a CASTRO, Jeanne Berrance de. A milícia cidadã:a Guarda Nacional de 1831 a 1850. $2^{a}$ ed. São Paulo: Cia. Editora Nacional, 1979 e URICOECHEA, Fernando. 0 minotauro imperial: a burocratização do Estado patrimonial brasileiro do século XIX. Rio de Janeiro/São Paulo: Difel, 1978. numero de ministros, o Supremo Tribunal de Justiça. Essa ascensão alternava o critério de antiguidade com o de merecimento, de modo que mesmo os que não estivessem politicamente apadrinhados no periodo tinham alguma oportunidade de subir. Os números foram aumentando ao longo do século XIX. Em 1851 havia no país 155 juízes de direito e 258 juízes municipais, ou seja, 413 juizes letrados, além de 68 magistrados de segunda instância, mais 17 ministros do Supremo Tribunal de Justiça, totalizando 498 magistrados. Em 1876 havia 399 juizes de direito, 469 juizes municipais, 44 juizes substitutos, 91 magistrados de segunda instancia e 17 ministros no Supremo Tribunal Federal totalizando 1.020 membros da carreira judicial. Portanto, em uma geração, havia dobrado o numero. Toda essa presença de magistrados constitui-se em meio a uma forte tensão, já que houve alguma continuidade entre os juizes vindos do período joanino, mas também houve uma reforma da justiça feita contra o que se consideravam os maiores defeitos da antiga magistratura. ${ }^{5}$

Se isso era assim quanto aos cargos da magistratura, quanto aos cargos auxiliares da justiça a situação era bastante diferente. Os ofícios de justiça demoraram muito a ganhar o estatuto burocrático moderno e, como se sabe, em alguns lugares do Brasil ainda não o ganharam. Escrivães e oficiais de justiça em geral continuaram a servir no híbrido sistema herdado do Antigo Regime. Em primeiro lugar não se integram num quadro hierárquico: um escrivão não progride numa escala de cargos. Em segundo lugar não são remunerados pelos cofres públicos: são pagos pelas partes que usam seus serviços, ou seja, recebem emolumentos. Em terceiro lugar não precisam ser letrados, basta serem práticos em direito. Finalmente, sobreviveu o costume, alheio a lei e a constituição, de indicarem alguém para servir em seu lugar, recebendo uma parte dos lucros do cargo. Em outras palavras, o oficio parecia-se com uma parte do patrimônio do oficial.

Outra carreira é a militar. Não surpreende também que seja estabelecida uma academia militar no Rio de Janeiro, logo depois da chegada da corte, em 1811. Aqui a trajetória brasileira parece distanciar-se do modelo hispanoamericano. De fato, a independência brasileira teve uma liderança civil, e desde muito cedo se desconfiou das forcas militares. 0 exército de linha, propriamente dito, mantinha ligações muito fortes seja com Portugal, seja com o Imperador, de modo que não tardou muito para ser reduzido. ${ }^{6}$ Em seu lugar surgiu a Guarda Nacional, com funções amplas de segurança e mesmo militares (como corpo auxiliar). ${ }^{7}$ Tanto assim que a legislação e a atividade administrativa do Império são pródigas em referências a cargos da Guarda Nacional. Não dispondo dos números, não tenho como comparar adequadamente os dados entre o mundo de língua espanhola e o mundo de língua portuguesa da América, mas suspeito que sejam diferentes. 0 trabalho de Wilma P. Costa aponta justamente para a oposição estrutural que havia entre um corpo burocrático, como o exército, e um sistema politizado (e, portanto, personalista e de alianças partidárias) como era a administração pública em geral.

No âmbito do governo, particularmente no Ministério do Império, havia também os quadros que se formavam. Desde o primeiro ministério do Brasil independente as carreiras de professor eram integradas na pasta do Império e aqui naturalmente os professores dos institutos de ensino superior compunham a ponta mais evidente desses quadros. A partir de 1860 também a carreira eclesiástica passou ao Ministério do Império. Os eclesiásticos formam, ao lado dos magistrados, a carreira mais extensa e mais bem organizada. Como os juizes, os padres precisavam de uma educação especial, embora não devamos idealizar a educação ministrada 
0 sistema era geral, pois também os juizes de direito recebiam vencimentos, parte das custas judiciais, e gratificações. nos seminários brasileiros, varias vezes referidos nos relatórios ministeriais como estando abandonados e em estado de decomposição. Os diversos cargos eclesiásticos, de vigário, pároco e cônego, para não falar de bispos, eram providos pelo Ministério, ouvido sempre o ordinário, que, por sua vez, era responsável pela organização dos concursos. Os padres iam para as freguesias ou paróquias depois de apresentarem seus títulos e serem julgados em função deles. 0 ministério do Império cuidava, portanto, de carreiras civis.

Os dados de que disponho não permitem afirmar que houvesse carreira de fazenda no Império. Havia os cargos no Ministério, na Corte, mas capilarmente o sistema, como nos ofícios de justiça, era dependente de particulares que se encarregavam das arrecadações por meio de contratos e depois prestavam contas junto aos tesoureiros. Alguma carreira se esboça nesses quadros das contadorias e tesourarias, pois desde a Reforma do Tesouro Régio (dezembro de 1761) levada a efeito por Pombal, o sistema de contabilidade exigido foi o de partidas dobradas, coisa que naturalmente só poderia ser dominada por gente adequadamente instruída. A mesma reforma levada a efeito por Pombal em 1761 impunha, no último titulo do alvará pelo qual El-Rei mandou-a executar, que os ofícios da Real Fazenda jamais seriam concedidos a título de propriedade, sem embargo do que dissesse ou alegasse alguém por direito "chamado Consuetudinário". Essa gente era formada nas aulas de comércio, também criadas no tempo de Pombal (em 19 de maio de 1759) e implantadas no Brasil por D. João ainda quando príncipe regente. Em 1827 criou-se uma Caixa de Amortização para administrar a dívida pública fundada. Estabelecida pela lei de 15 de novembro de 1827, a Caixa deveria contar com um inspetor-geral, um contador, um tesoureiro, um corretor e dois escriturários (art. 47). Impunha-se que o inspetor-geral fosse "amestrado em contabilidade e arrumação de livros, giro de câmbios e redução de diferentes moedas tendo, além disso, conhecimentos gerais da ciência econômica." (art. 48) Reformas seguiram-se depois da abdicação, com a lei de 4 de outubro de 1831 que reorganizou o Tribunal do Tesouro Público Nacional. Mas ainda se nota que a arrecadação era deixada aos particulares, pois o Tribunal apenas fixaria as condições de arrematação das rendas e dos contratos. A burocracia estatal, entretanto, já aqui também estava mais nitidamente aparecendo, pela exigência de que os empregados demonstrassem aptidões específicas: idioma nacional, cálculo mercantil, contabilidade em partidas dobradas, boa letra. Em 1844 passou-se a fiscalização das rendas públicas dos juízes 'territoriais' (ou seja, juizes do poder judiciário) para as Mesas de Coletoria. Em 1850, pela lei 563 (regulamentada pelo Decreto 736 e mais tarde pelo Decreto 870, de 1851), reorganizou-se parte do sistema, fixando o papel das Tesourarias das províncias. No mesmo ano de 1850 passava-se a exigir formalmente dos empregados do Tesouro a demonstração de que dominavam o idioma nacional, a aritmética e a contabilidade por partidas dobradas. Ainda em 1879 o ministro Afonso Celso, visconde de Ouro Preto, sugeria que se refinasse a burocracia, propondo que os funcionários da Fazenda fossem admitidos por meio de um concurso público, aumentando-Ihes os vencimentos. Até então os administradores das rendas eram remunerados pela soma de diversas fontes: a) com participação nos valores arrecadados, b) com ordenados ou vencimentos propriamente ditos e c) com gratificações pelo exercício das funções. ${ }^{8}$

Hoje chamamos carreira a um conjunto hierarquizado de postos (cargos públicos), articulados por uma finalidade ou função geral atribuída ao órgão a que pertencem, aos quais se chega por meio de concursos públicos, com provas especificas de habilidades para a função ou tarefa, e nos quais se 
ascende ou se progride, por métodos alternados de antiguidade e merecimento. No caso do Brasil, essa carreira é ainda contemplada com um regime de estabilidade, de modo a isolar o corpo funcional permanente das alterações de cúpula promovidas pelo sistema eleitoral. Essa organização ganhou forma mais ou menos final no governo de Getúlio Vargas, não só pela criação do Departamento de Administração do Serviço Público, como também pela inclusão do tema na Constituição de 1934 (art.168-173) como título específico da lei maior. Dessa forma, a existência da burocracia estatal como a conhecemos hoje, tem cerca de sete décadas.

Vou concluir com um traço que me parece fundamental para entender o que houve em termos de burocracia de Estado no século XIX. O constitucionalismo oitocentista estava determinado por certa compreensão das funções de Estado, particularmente da ideia de que o governo, sendo representativo, não deveria ter ofícios, funções ou cargos de propriedade de ninguém. Esse ideal conflitava diretamente com os quadros vindos do regime anterior. Não surpreende, portanto, que no ano de 1827 (durante o funcionamento da primeira Assembleia Geral, instalada em 1826), fossem feitas tantas alterações importantes em nosso direito público. A lei de 15 de outubro de 1827, por exemplo, pretendia uma reforma profunda, pela qual os "ofícios" de justiça e fazenda não fossem mais apropriados por ninguém a título de propriedade. Essa concepção 'proprietária' do cargo (prebendária, diria Weber) era tão forte que mesmo os juizes vitalícios eram chamados de juizes proprietários do cargo, coisa que naturalmente choca nossos ouvidos contemporâneos, mas é um bom indício da ideia completamente diversa que se fazia dos cargos públicos ao longo de boa parte do século XIX. Os ofícios não eram, portanto, nem cargos, nem empregos. Transformá-los em empregos públicos ou em cargos públicos seria a tarefa do século XIX, tarefa que, no caso brasileiro, só se consolidou depois da Revolução de 1930. Voltando ao ponto: durante 0 século XIX surgiu, mas não espontânea nem imediatamente, uma burocracia não prebendaria, não patrimonialista. 0 primeiro lugar onde essa burocracia surgiu, segundo creio, foi no Judiciário: porque o exercício dos empregos de justiça foi limitado a quem tivesse uma educação formal específica e porque foi garantido o exercício pro vita do cargo. Mas nos lugares em que o exercicio estável, pro vita, era rejeitado, a burocracia custou a surgir, ou não surgiu propriamente. E a falta dessa burocracia estável, profissional, isolada das viradas políticas, só tardiamente começou a ser notada. No início do século XIX o que houve foi a luta contra uma burocracia estável, "proprietária" de seus cargos, insensivel e irresponsável diante das mudanças ocorridas nos altos cargos políticos. 0 que se formou em primeiro lugar, portanto, foi a burocracia dos cargos demissiveis ad nutum, dos cargos de confiança, dos cargos de deliberação e dos cargos ligados a atividades-meio antes que a atividades-fim do Estado. Essa burocracia era instável, política e, portanto, não profissional. Isso explica o célebre dito do Visconde do Uruguai: "Este é o grande defeito das nossas administrações. Têm grande luxo de pessoal. Têm cabeças enormes, quase não têm braços e pernas. (...) Ver-se-á que nossa organização administrativa peca pela falta de meios de ação. É uma cabeça enorme em um corpo entanguido." (p. 205) Esse diagnóstico revela a descontinuidade no próprio conceito de burocracia: de um corpo de auxiliares direto do soberano para um corpo de serviço permanente do Estado e, em alguns casos, de prestação direta de serviços aos cidadãos. Não foi pequena a mudança. Para recontar - e compreender - essa história, o desafio proposto pelo Prof. Garavaglia ainda está em boa parte por ser respondido. 